\title{
Effect of Carbohydrate and Corticosteroids on Activity of $\alpha$-Glucosidases in Intestine of the Infant Rat
}

\author{
Emanuel Lebenthal, Phimip Sunshine, and Norman Kretchmer \\ From the Department of Pediatrics, Stanford University, \\ Stanford, California 94305
}

\begin{abstract}
A в S TRACT The activities of intestinal sucrase and isomaltase are not detectable in rats before 15-16 days of age, but administration of corticosteroids precociously induces the activities of these two $\alpha$-glucosidases. 9-day old rats were removed from their mothers, warmed in an incubator, and fed by constant infusion through gastrostomies. The basic diet was a soya preparation to which various sugars were added. When the diet contained $2 \%$ sucrose, diarrhea ensued for $48 \mathrm{hr}$, but subsided when intestinal sucrase and isomaltase appeared precociously. In animals fed sucrose, the activities of sucrase and isomaltase were markedly increased as compared to animals on carbohydrate-free diets (sucrase $2.41 \pm 0.23$ vs. $0.63 \pm$ $0.13 \mathrm{U}$, isomaltase $3.43 \pm 0.42$ vs. $0.78 \pm 0.18 \mathrm{U}$ ). Maltase activity was doubled, while lactase was not altered significantly. The mitotic index of crypt cells, the depth of crypts, and incorporation of thymidine- ${ }^{3} \mathrm{H}$ into DNA were increased. In adrenalectomized rats, activities of sucrase and isomaltase were not detected nor induced by sucrose. Steroids given to adrenalectomized rats caused appearance of the enzymes; but if cortisone and sucrose were given together, there was synergism evidenced by a marked increase in activities (sucrase $7.2 \pm 1.1$ vs. $0.68 \pm 0.12 \mathrm{U}$ ). In contrast to observations in adult animals, the effect of sucrose on $\alpha$-glucosidases in developing animals demands the participation of the adrenal gland.
\end{abstract}

\section{INTRODUCTION}

Lactase is very active in the intestine of the newborn rat, but then gradually decreases so that by the end of

Dr. Lebenthal is a Postdoctoral Research Fellow on leave from the Beilenson Medical Center, Tel-Aviv Medical School, Israel.

This study was presented in part at the 1971 Annual Meeting of the Society for Pediatric Research in Atlantic City, N. J.

Received for publication 5 November 1971 and in revised form 21 December 1971. the suckling period the activity is very low (1-4). In contrast, the activities of the intestinal $\alpha$-glucosidases are either very low (maltase) or undetectable (sucrase and isomaltase) during the early suckling period (2, 3, 5). Sucrase and isomaltase appear by the 15 th to 21 st postnatal day, and attain adult values by the 30 th postnatal day $(2,3,5)$. Similar developmental patterns for the disaccharidases have been observed in the intestine of pigs (6), cows (7), and dogs (8) in contrast to the human in whom all of the intestinal disaccharidases are present and active before birth (9-11).

Precocious development of intestinal sucrase and isomaltase in rats can be stimulated by injection of corticosteroids before the time these enzymes would normally appear (5). Simultaneously with these biochemical changes, the morphology of the intestine is altered so that it displays a more mature histological appearance, similar to that found in the adult animal (3).

Recently it was observed that when adult humans were fed high concentrations of sucrose, there was an increase in the activities of intestinal sucrase and maltase (12). Likewise, when elevated dietary carbohydrate was fed to fasted adult rats for $24 \mathrm{hr}$, there was a twofold increase in the activities of sucrase and maltase $(13,14)$. Neither adrenalectomy nor administration of steroids had an effect on the activities of the disaccharidases in the adult animal (14).

In the present investigation, we have utilized the suckling rat to study changes in activities of intestinal disaccharidases and in cellular proliferation of jejunal mucosa in response to alterations in dietary content of carbohydrates, to adrenalectomy, and to the administration of adrenal corticosteroids.

\section{METHODS}

Animals. The size of each litter of Wistar rats used in these experiments was reduced to eight animals 2 days after birth. The infant rats were removed from their mothers at 9 days of age. Some of these animals were subjected to 
gastrostomy and others were utilized as nonoperated controls. All the animals were fasted for 16-24 hr. Those infant rats that received a gastrostomy were kept in an incubator during this fasting period. Some of the operated animals were then returned to their mother, and the remainder of the infant rats with the gastrostomy were maintained in the incubator and fed continuously utilizing a pump.

Other groups of rats were removed from their mothers for 16-24 hr, fasted, and then returned to their mothers for nursing. These animals were fed also by gastric gavage with either various amounts of carbohydrates or water.

Artificial feeding by continuous gastric infusion. A complex polyethylene-silicone cannula was placed in the stomach via gastrostomy, using a modification of the technique developed by Messer, Thomas, Terrasa, and Dallman (15). Messer and coworkers used a catheter composed of five separate components. In the present experiments, a 4 unit tube was constructed which omitted the polyethylene doughnutshaped disc, since the disc produced kinking of the catheter. Also, the stomach was grasped by purse-string sutures instead of by tissue forceps to prevent unnecessary trauma to the organ. An additional suture was placed around the tube and through the stomach to anchor the cannula firmly. The tube was guided between the muscle layers of the abdomen, around the trunk, and brought out through the skin on the dorsum of the animal. These procedures allowed the animals free movement and also prevented inadvertent removal of the tube. The animals were fasted for $24 \mathrm{hr}$, and the cannulae were connected to an infusion pump modified to hold eight $5 \mathrm{ml}$ syringes, so that the animals could be fed continuously. Control littermates were subjected to the same surgical procedure, but after insertion of the cannulae, they were returned to their mothers for nursing. Wherever possible, littermates were used throughout this study.

Urination and defecation had to be stimulated at least every $8 \mathrm{hr}$ by wiping and light stroking of the urethral papilla and anus.

Basic diet. The basic diet was a carbohydrate-free soybean formula ( $\mathrm{CHO}$ Free, Borden, Inc. (Pharmaceutical Products), New York), which provided 23 cal per fluid ounce. This formula contained $3.6 \%$ protein and $7.0 \%$ fat. The infusion rate was $6-8 \mathrm{ml}$ in $24 \mathrm{hr}$, providing $250-310$ $\mathrm{cal} / \mathrm{kg}$ body weight per day.

During the study, varying amounts of carbohydrates were added to the basic formula, but each diet was maintained isocaloric by varying dietary content of fat and protein (Table I). On the first day of the study, $2 \%$ sucrose was added to the basic diet; on the second and third days, $4 \%$, and on the fourth day, $6 \%$ sucrose.

Intermittent feeding by gastric gavage. The animals that were fed intermittently by gavage received $0.7 \mathrm{ml}$ of carbohydrate solution four times a day, beginning with $2 \%$ the first day, $4 \%$ on the second and third days, and $6 \%$ on the fourth day. Control littermates received tap water by gastric gavage. These two groups of animals were nursed by their mothers.

Adrcnalcctomy and cortisone acetate administration. One group of suckling animals was adrenalectomized simultaneously with the placement of the gastric cannula. The operative approach was through an incision $1.5-2 \mathrm{~cm}$ in length, in the mid-back, providing sufficient access for both gastrostomy and adrenalectomy. The adrenalectomized animals were fed the basic $\mathrm{CHO}$-free diet supplemented with $1.0 \% \mathrm{NaCl}$. The mortality rate with this procedure was very
TABLE I

Composition of Diets Fed to Infant Rats by Gastrostomy

\begin{tabular}{llccccccc}
\hline Constituent & $\%$ & Calories & $\%$ & Calories & $\%$ & Calories & $\%$ & Calories \\
\hline Carbohydrate & 0 & 0 & 2.0 & 8 & 4.0 & 16 & 6.0 & 24 \\
Protein & 3.6 & 14 & 3.2 & 13 & 3.0 & 12 & 2.5 & 10 \\
Fat & 7.0 & 63 & 6.3 & 57 & 5.6 & 50 & 4.9 & 44 \\
$\begin{array}{l}\text { Total calories } \\
\text { per 100 ml }\end{array}$ & & 77 & & 78 & & 78 & & 78 \\
\hline
\end{tabular}

high and only 3 of 24 rats survived the surgery for the entire study. Another group of infant rats was adrenalectomized at 10 days of age, returned to their mother and received additional carbohydrates supplemented with $1 \%$ $\mathrm{NaCl}$ by gastric gavage.

A third group of animals was adrenalectomized and given i.p. injections of cortisone acetate, $15 \mathrm{mg} / \mathrm{kg}$ per day for 4 days.

A fourth group was adrenalectomized and received additional carbohydrate via gastric gavage with an i.p. injection of cortisone acetate. Sham-operated, nonadrenalectomized controls were maintained with each of these preceding groups of animals.

Assays of disaccharidases. The animals were killed at 14 days of age, 4 days after initiation of the study. The intestine from the ligament of Treitz to the cecum was removed, washed, and homogenized in 4 vol of ice-cold $0.9 \% \mathrm{NaCl}$.

Sucrase, isomaltase, maltase, and lactase activities were determined by a modification of the method described by Doell and Kretchmer (5). Substrate concentrations were: lactose, $0.6 \mathrm{M}$; maltose, $0.112 \mathrm{M}$; sucrose, $0.28 \mathrm{M}$; and isomaltose, $0.2 \mathrm{M}$. Assays were carried out in $0.1 \mathrm{M}$ maleate buffer, $\mathrm{pH} 5.8$, and were terminated by addition of equal volumes of barium hydroxide $(1.8 \%)$ and zinc sulfate $(2 \%)$. The concentration of glucose released in the assays was determined by a semi-micro method using the Glucostat ${ }^{\circledR}$ reagent (Worthington Biochemical Corp., Freehold, N. J.). Protein was measured by the Oyama and Eagle (16) modification of the method of Lowry, Rosebrough, Farr, and Randall (17). $1 \mathrm{U}$ of activity is equal to $1 \mu$ mole of disaccharide hydrolyzed per hour per $\mathrm{mg}$ protein at $37^{\circ} \mathrm{C}$.

Evaluation of cellular proliferation. Samples of jejunum were fixed in $10 \%$ formalin. Multiple histological sections were scanned, and those areas where the section passed through the entire vertical length of a villus and crypt were evaluated without prior knowledge of the previous experimental procedure.

The height of the villus and the depth of the crypt column were determined in 10 villi and crypts per animal as described by Herbst and Sunshine (3). To minimize errors caused by shrinkage of tissues during preparation of the sections, distances were measured by counting the number of cells lining one side of a villus or one side of a crypt column with a magnification of $640 \times$. The mitotic index was calculated by counting 1000 crypt cells in each slide, and noting the percent of cells undergoing mitosis.

The labeling index was determined by the radioautographic technique of Kopriwa and Leblond (18). The animals were given $2 \mu \mathrm{Ci}$ of tritiated thymidine (SA $2.0 \mathrm{Ci} / \mathrm{mmole}$ ) per $\mathrm{g}$ body weight i.p., and killed $4 \mathrm{hr}$ later. The labeled crypt cells indicated those cells which were actively synthesizing DNA. 


\section{RESULTS}

Growth. Both the weights of the animals and of the jejunum and ileum are shown in Table II. All animals that had gastrostomies or adrenalectomies had lower rates $(P<0.01-0.001)$ of weight gain in comparison with unoperated controls. Adrenalectomized animals receiving sucrose manifested a loss of weight. Although there was a variability in the weights of the jejunum and ileum between the groups of animals studied, the concentration of protein per gram of wet weight of the intestine remained constant. The weights of the animals were, in general, reflected in the rate of growth of the jejunum and ileum.

Effect of gastrostomy, adrenalectomy, and dietary su- crose on intestinal disaccharidases. In 18 infant rats that underwent gastrostomy but were nursed and in 13 animals with gastrostomies that were fed a CHO-free diet, the activities of sucrase, isomaltase, and maltase were elevated $(P<0.001)$ as compared with 20 unoperated controls (Table III). There was a decrease in the activity of intestinal lactase in those animals fed a CHOfree diet via gastrostomy as compared with unoperated controls and those that were operated and nursed by their mothers.

Introduction of $2 \%$ sucrose by gastrostomy caused the animals to develop diarrhea which lasted $48 \mathrm{hr}$ and disappeared when the activities of intestinal sucrase and isomaltase increased remarkably (Table III). In animals fed sucrose, the activities of intestinal sucrase and iso-

TABLE II

Body Weight, Weight of Jejunum and Ileum, and Protein Content of Intestine in the Experimental Groups of Animals

\begin{tabular}{lccccc}
\hline \multicolumn{1}{c}{ Group } & $\begin{array}{c}\text { Weight } \\
\text { 10 days old }\end{array}$ & $\begin{array}{c}\text { Weight } \\
\text { 14 days old }\end{array}$ & $\begin{array}{c}\text { Weight } \\
\text { gain }\end{array}$ & $\begin{array}{c}\text { Weight of } \\
\text { jejunum and } \\
\text { ileum }\end{array}$ & $\begin{array}{c}\text { mg protein } \\
\text { per g small } \\
\text { intestine }\end{array}$ \\
\hline & $g$ & $g$ & $g$ & $m g$ & \\
Controls (20)* & $20.3 \pm 2.1$ & $26.9 \pm 2.2$ & $6.6 \pm 0.4$ & $1080 \pm 75$ & $102.9 \pm 2.5$ \\
Oper/nursed (18) & $20.5 \pm 1.9$ & $24.1 \pm 3.1$ & $3.6 \pm 0.3 \ddagger$ & $970 \pm 40$ & $105.3 \pm 4.2$ \\
Oper/CHO-free diet (13) & $20.3 \pm 2.3$ & $21.5 \pm 2.0$ & $1.2 \pm 0.1 \S$ & $815 \pm 65$ & $103.5 \pm 2.1$ \\
Oper/sucrose (16) & $19.8 \pm 1.4$ & $21.1 \pm 2.0$ & $1.3 \pm 0.1 \S$ & $750 \pm 45$ & $107.7 \pm 4.0$ \\
Oper/sucrose/ADX (3) & $20.1 \pm 0.7$ & $19.2 \pm 1.1$ & $-0.9 \pm 0.2 \S$ & $900 \pm 35$ & $105.2 \pm 3.6$ \\
Sucrose by gavage (11) & $19.4 \pm 1.8$ & $25.0 \pm 1.8$ & $5.7 \pm 0.6$ & $1240 \pm 70$ & $101.5 \pm 2.9$ \\
ADX/cortisone (3) & $19.2 \pm 1.8$ & $26.4 \pm 2.5$ & $6.2 \pm 0.6$ & $1110 \pm 45$ & $100.3 \pm 4.8$ \\
ADX/NaCl (4) & $19.8 \pm 2.0$ & $22.5 \pm 1.2$ & $2.7 \pm 0.3 \ddagger$ & $1100 \pm 55$ & $101.8 \pm 1.0$ \\
ADX/sucrose (7) & $20.6 \pm 1.8$ & $20.1 \pm 1.8$ & $-0.5 \pm 0.1 \S$ & $970 \pm 30$ & $109.8 \pm 3.8$ \\
ADX/cortisone/sucrose (4) & $19.4 \pm 0.5$ & $26.5 \pm 2.6$ & $7.1 \pm 0.9$ & $1130 \pm 20$ & $97.0 \pm 0.5$ \\
\hline
\end{tabular}

Oper, infant rats with gastrostomy; CHO-free, carbohydrate-free diet; ADX, adrenalectomized infant rats. Each value represents the mean \pm SEM.

* Number of rats in parentheses.

$\ddagger P<0.01$.

$\S P<0.001$ as compared with control animals.

TABLE III

Effect of Gastrostomy, Adrenalectomy, and Dietary Sucrose on Intestinal Disaccharidases

\begin{tabular}{lcccc}
\hline \multicolumn{1}{c}{ Group } & Sucrase & Isomaltase & Maltase & Lactase \\
\hline & & $\mu$ moles & disaccharide & hydrolyzed $/ \mathrm{hr}$ per mg protein \\
Controls (20)* & 0 & 0 & $1.7 \pm 0.07$ & $4.9 \pm 0.18$ \\
Oper/nursed (18) & $0.33 \pm 0.07^{*}$ & $0.52 \pm 0.05 \ddagger$ & $4.2 \pm 0.67 \ddagger$ & $4.5 \pm 0.31$ \\
Oper/CHO-free (13) & $0.63 \pm 0.13^{*}$ & $0.78 \pm 0.16 \ddagger$ & $4.8 \pm 0.53 \ddagger$ & $3.9 \pm 0.38$ \\
Oper/sucrose (16) & $2.4 \pm 0.23 \S$ & $3.4 \pm 0.42 \S$ & $10 \pm 0.68 \S$ & $3.6 \pm 0.25$ \\
Oper/sucrose/ADX (3) & 0 & 0 & $1.7 \pm 0.12$ & $2.1 \pm 0.12 \ddagger$
\end{tabular}

Oper, infant rats with gastrostomy; CHO-free, carbohydrate-free diet; ADX, adrenalectomized rats. Each value represents the mean \pm SFM.

* Number of rats in parentheses.

$\ddagger P<0.001$ as compared with the control animals.

$\S P<0.001$ as compared with the animals operated and fed by a Borden CHO-free diet. 
TABLE IV

Effect of Intermittent Sucrose Feeding, Adrenalectomy, and Cortisone on Intestinal Disaccharidases

\begin{tabular}{lccc}
\hline \multicolumn{1}{c}{ Group } & Sucrase & Maltase & Lactase \\
\hline & \multicolumn{3}{c}{$\mu$ moles disaccharide hydrolyzed/ } \\
& \multicolumn{3}{c}{ hr per mg protein } \\
Controls (20)* & 0 & $1.7 \pm 0.07$ & $4.9 \pm 0.18$ \\
Sucrose (11) & $0.68 \pm 0.12 \ddagger$ & $3.5 \pm 0.35 \ddagger$ & $3.7 \pm 0.29 \ddagger$ \\
Control/ADX (4) & 0 & $1.8 \pm 0.10$ & $4.0 \pm 0.42$ \\
Sucrose/ADX (7) & 0 & $1.7 \pm 0.02$ & $2.3 \pm 0.08 \ddagger$ \\
Cortisone/ADX (3) & $1.4 \pm 0.14 \ddagger$ & $8.6 \pm 0.30 \ddagger$ & $4.0 \pm 0.64$ \\
Cortisone/sucrose/ADX (4) & $7.2 \pm 1.1 \S$ & $18.0 \pm 1.9 \$$ & $2.9 \pm 0.13 \ddagger$ \\
& & & \\
\hline
\end{tabular}

ADX, adrenalectomized infant rats. Each value represents the mean \pm SEM. * Number of rats in parentheses.

I $P<0.01-0.001$ as compared with control animals.

$\$ P<0.001$ compared with sucrose fed animals.

maltase were significantly increased $(P<0.001)$ as compared with those animals receiving a carbohydratefree diet. The activity of maltase doubled while that of lactase was unchanged.

In adrenalectomized animals that received sucrose by gastrostomy, the activities of intestinal sucrase and isomaltase were undetectable and were similar to that of unoperated controls. Activity of maltase did not change. Activity of intestinal lactase of these adrenalectomized animals was significantly lower $(P<0.001)$ than any other group.

When lactose was substituted for sucrose and fed at concentrations of $3 \%$ and $6 \%$, the activity of intestinal sucrase, maltase, and lactase were similar to that of the animals fed the basic $\mathrm{CHO}$-free diet via gastrostomy.

If maltose was substituted for sucrose and fed at $2 \%$, $4 \%$, and $6 \%$ concentrations via gastrostomy, the activities of maltase and lactase were similar to those found in animals fed sucrose via gastrostomy; but the activity of sucrase was only half that of the animals fed sucrose.
Effect of intermittent sucrose feeding, adrenalectomy, and cortisone on intestinal disaccharidases. In animals fed sucrose by gastric gavage, the activities of sucrase and maltase were increased as compared with controls, while the activity of lactase was slightly decreased (Table IV). In adrenalectomized rats, the feeding of sucrose did not cause an increase in the activities of sucrase and maltase, but the activity of lactase was decreased significantly $(P<0.001)$. Steroids given to adrenalectomized rats caused appearance of sucrase and a rise in maltase $(P<0.001)$; but, if cortisone and sucrose were given together there was a synergistic effect, which was reflected in a marked increase $(P<0.001)$ in the activities of the $\alpha$-glucosidases. Concomitantly, the activity of lactase decreased $(P<0.05)$ in comparison with both the adrenalectomized animals and the adrenalectomized animals that received cortisone.

Cellular proliferation of the jejunal mucosa. The depth of the crypt, the labeling index, and the mitotic index were greater $(P<0.01-0.001)$ in the animals fed sucrose by gastrostomy as compared with controls and to animals which were fed the CHO-free diet via gastrostomy (Table V). The ratio of the height of the villus to the depth of the crypt decreased significantly $(P<0.001)$ when the animals were fed sucrose.

The jejunum of the animals that were fed sucrose intermittently by gavage also had a significant increase $(P<0.001)$ in the depth of the crypts and a decrease $(P<0.001)$ in the villi-crypt ratio (Table VI). The increase in the labeling index and mitotic index was not significantly altered $(P<0.2)$.

A profound change in all the indices of cellular proliferation was found in animals fed sucrose and given daily injections of cortisone acetate. In these animals, the depth of the crypt, the labeling index, and mitotic index were increased $(P<0.001)$ in comparison with controls and with animals receiving sucrose alone.

TABLE V

Effect of Continuous Sucrose Diet and Adrenalectomy on Jejunal Proliferation

\begin{tabular}{|c|c|c|c|c|c|}
\hline Group & $\begin{array}{l}\text { No. of } \\
\text { animals }\end{array}$ & $\begin{array}{l}\text { Depth of } \\
\text { the crypt* }\end{array}$ & $\begin{array}{l}\text { Labeling } \\
\text { index } f\end{array}$ & $\begin{array}{c}\text { Mitotic } \\
\text { indexई }\end{array}$ & $\begin{array}{l}\text { Ratio height of } \\
\text { villi/crypt } \|\end{array}$ \\
\hline Controls & 20 & $9.6 \pm 4.0$ & $6.5 \pm 4.4$ & $3.7 \pm 2.3$ & $6.1 \pm 1.3$ \\
\hline Oper/CHO-free diet & 13 & $12.0 \pm 2.9$ & $8.1 \pm 2.0$ & $4.6 \pm 2.5$ & $5.3 \pm 1.3$ \\
\hline Oper/sucrose & 16 & $19.8 \pm 5.29$ & $10.9 \pm 3.0 \top$ & $7.1 \pm 2.2 \pi$ & $3.6 \pm 0.9$ ๆ \\
\hline Oper/sucrose/ADX & 3 & $9.3 \pm 0.9$ & $5.7 \pm 0.9$ & $3.3 \pm 0.9$ & $5.6 \pm 0.6$ \\
\hline
\end{tabular}

Each value represents the mean $\pm \mathrm{SD}$.

* Number of cells lining one side of crypt.

$\ddagger$ Number of cells in each crypt undergoing DNA synthesis.

$\S$ Percent of cells undergoing mitosis.

|| Number of cells lining one side of villi and crypt column.

If $P<0.01-0.001$ as compared with controls and oper/CHO-free diet. 
TABLE VI

Effect of Adrenalectomy, Corticosteroids, and Intermittent Sucrose Diet on Jejunal Proliferation

\begin{tabular}{|c|c|c|c|c|c|}
\hline Group & $\begin{array}{c}\text { No. of } \\
\text { animals }\end{array}$ & $\begin{array}{l}\text { Depth of } \\
\text { the crypt* }\end{array}$ & $\begin{array}{c}\text { Labeling } \\
\text { index } \$\end{array}$ & $\begin{array}{r}\text { Mitotic } \\
\text { indexई }\end{array}$ & $\begin{array}{l}\text { Ratio height of } \\
\text { villi/crypt }\end{array}$ \\
\hline Controls & 20 & $9.6 \pm 4.0$ & $6.5 \pm 4.4$ & $3.7 \pm 2.3$ & $6.10 \pm 0.9$ \\
\hline Sucrose $2-6 \%$ & 11 & $16.6 \pm 2.0 \pi$ & $8.5 \pm 3.3$ & $5.8 \pm 2.0$ & $4.41 \pm 0.3 \uparrow$ \\
\hline Sucrose/ADX & 7 & $9.0 \pm 2.5$ & $5.4 \pm 2.3$ & $3.4 \pm 1.4$ & $6.2 \pm 0.7$ \\
\hline Sucrose/cortisone/ADX & 4 & $27.5 \pm 4.6 \pi$ & $21.3 \pm 4.1 \rrbracket$ & $8.7 \pm 1.79$ & $2.8 \pm 0.4$ \\
\hline $\mathrm{ADX} /$ cortisone & 3 & $19.7 \pm 3.7 \pi$ & $15.3 \pm 2.49$ & $6.7 \pm 0.9 ף$ & $3.6 \pm 0.1$ \\
\hline
\end{tabular}

Each value represents the mean \pm SD.

* Number of cells lining one side of crypt.

$\ddagger$ Number of cells in each crypt undergoing DNA synthesis.

$\S$ Percentage of cells undergoing mitosis.

|| Number of cells lining one side of villi and crypt column.

II $P<0.01-0.001$ as compared with controls.

\section{DISCUSSION}

The major finding of these experiments was to indicate clearly that the ability to adapt to changes in diet, in this case, carbohydrates, is much different in the suckling animal than it is in the adult.

These studies were made possible by the institution of a feeding procedure, through a gastrostomy, so that suckling animals could be separated from their mothers. Under these conditions, the diet could be readily adjusted to vary both the nature and concentration of carbohydrates. The animals could be nourished so that they gained weight, although their rates of growth were not as great as those of the control animals.

When sucrose or maltose was fed to the animal, regardless of whether the animal was fed continuously via gastrostomy or intermittently by gastric gavage, there was a precocious appearance of intestinal sucrase and isomaltase. The increase in the activities of the intestinal $\alpha$-glucosidases in suckling animals that were fed sucrose or maltose was similar to the findings of Blair, Yakimets, and Tuba (13) and Deren, Broitman, and Zamcheck (14) with adult rats, and Rosensweig and Herman (12) with adult humans. The basic difference between our data and theirs is that the activity of sucrase and isomaltase in the suckling rat was undetectable before the time sucrose was introduced into their diet.

When the animals were subjected to surgery, e.g. gastrostomy, the activity of sucrase was detectable even though no substrate was given. This result is presumed to be related to the effect of stress on the animal. Doell and Kretchmer (5) studied the development of sucrase and reported that steroids, administered before the time that the enzyme would have normally appeared in the intestine, caused a precocious appearance of intestinal sucrase. Based on this information, we assume that the stress of gastrostomy or diarrhea could be sufficient to result in the release of adrenocortical steroids which would then cause the precocious appearance of sucrase and isomaltase.

The role of the adrenal gland in the adaptive appearance of sucrase was shown using adrenalectomized animals. In adrenalectomized animals, there were no detectable activities of the enzymes sucrase or isomaltase even postoperatively. If the adrenalectomized animals were fed sucrose, there was no effect of the substrate upon the activity of any of the $\alpha$-glucosidases even though the animals developed diarrhea. When cortisone was given to these animals, the $\alpha$-glucosidases increased in activity. The most interesting finding was that when cortisone and sucrose were administered concomitantly to the adrenalectomized animal, there was a synergistic effect so that the activity of the enzymes increased markedly. These findings are considerably different from those reported by other workers (14) who showed that in adult animals there is no effect upon the enzymatic activities with either adrenalectomy or administration of corticosteroids.

The over-all morphological changes during the induction of the $\alpha$-glucosidases, as measured by the mitotic index, the labeling index, the depth of the crypt and the villus-crypt ratio, indicated that in accord with the appearance of the enzymes, the histological appearance of the intestine more closely resembled that of the mature animal than that of the infant.

It is possible to postulate a potential mechanism by which the intestine adapts to dietary changes. In the adult rat $(13,14)$, it has been shown that only the carbohydrate is effective in causing an increase in activities of the $\alpha$-glucosidases. In the infant rat, as demonstrated in this investigation, the substrate had an effect on the activity of the enzyme, but adrenocortical hormones were also active participants in the capability for the intestine to adapt to dietary carbohydrate.

In either the adult or the infant rat, administration 
of the sucrose may have resulted in an increase of the activities of sucrase, isomaltase, and maltase by any number of mechanisms, one of which could have been a decrease in the rates of degradation of the enzymes (19). In the suckling rat, there was also an increase in the activities when adrenal hormones were given, and the substrate had no effect when the rat was adrenalectomized. On the basis of other observations $(20,21)$, it is possible that the hormone acted directly to stimulate synthesis of the enzyme. There are a number of comparisons that can be made during development between the biochemical data obtained from intestine and liver. Various aspects of enzymatic changes encountered in the liver during development have recently been reviewed (22), particularly in reference to the effects of glucocorticoids on the enzymes. The differences in the response and the complexities of the action of the glucocorticoids vary in both organs relative to the enzyme and also to the stage of development of the organism. There are enzymes such as glucose-6-phosphatase in liver, and intestinal lactase which appear during fetal life but which are not influenced by exogenously administered glucocorticoids.

Those enzymes which develop during the suckling period in rat, as typified by hepatic ornithine transaminase $(23,24)$ and intestinal sucrase (5), are particularly sensitive to exogenous glucocorticoids which result in a precocious increase in activity of these enzymes before the expected time of the natural developmental burst of activity. Sucrase is particularly unique since there is no immunochemical or biochemical evidence of the enzyme until the glucocorticoid is administered or until the natural time of appearance (25). Since adrenalectomy affects the appearance of the activity of both of these enzymes, it is probable that the glucocorticoids are acting physiologically at a locus which is presently unknown. Also, in both cases glucocorticoids have little effect after the enzyme is fully developed. From the available data, it is conceivable that the glucocorticoids stimulate at some phase during the synthesis of the enzyme and that after the enzyme, such as sucrase, has attained the activity indicative of the mature organ the substrate, sucrose, acts to decrease the degradative rate of the protein (26). Consequently, in the suckling rat, adrenocortical hormones and sucrose given together act synergistically by resulting in a large increase in activities of the $\alpha$-glucosidases.

These data indicate a significant and important difference in the mechanism between the ability of intestine of the suckling animal and that of adult animals to adapt to dietary change. Further studies of dietary adaptations should consider the biological differences that could exist between the developing organism and the fully established mature animal.

\section{ACKNOWLEDGMENTS}

This investigation was supported in part by National Institutes of Health Grants HD-02147, HD-00049, HD-00391, and RR 81.

\section{REFERENCES}

1. Doell, R. G., and N. Kretchmer. 1962. Studies of small intestine during development. I. Distribution and activity of $\beta$-galactosidase. Biochim. Biophys. Acta. 62: 353.

2. Rubino, A., F. Zimbalatti, and S. Auricchio. 1964. Intestinal disaccharidase activities in adult and suckling rats. Biochim. Biophys. Acta. 92: 305.

3. Herbst, J. J., and P. Sunshine. 1969. Postnatal development of the small intestine of the rat. Pediat. Res. 3:27.

4. Hsia, D. Y. Y. 1966. The development of intestinal $\beta$ galactosidase and $\beta$-glucuronidase in the newborn. Biochim. Biophys. Acta. $122: 550$.

5. Doell, R. G., and N. Kretchmer. 1964. Intestinal invertase: precocious development of activity after injection of hydrocortisone. Science (Washington). 143: 42.

6. Dahlqvist, A. 1961. Intestinal carbohydrases of a newborn pig. Nature (London). 190: 31 .

7. Huber, J. T., N. L. Jacobson, and R. S. Allen. 1961 Digestive enzyme activities in the young calf. J. Dairy Sci. 44 : 1494.

8. Welsh, J. D., and A. Walkner. 1965. Intestinal disaccharidase and alkaline phosphatase activity in the dog. Proc. Soc. Exp. Biol. Med. 120: 525.

9. Heilskov, N. S. C. 1952. Studies on animal lactase. II. Distribution in some of the glands of the digestive tract. Acta Physiol. Scand. 24 : 84.

10. Fomina, L. S. 1960. The activities of some enzymes in the intestine and other organs of human foetus. $V o p$. Med. Khim. 6: 176 (in Russian).

11. Auricchio, S., A. Rubino, and G. Mürset. 1965. Intestinal glycosidase activities in the human embryo, fetus, and newborn. Pediatrics. 35 : 944.

12. Rosensweig, N. S., and R. H. Herman. 1968. Control of jejunal sucrase and maltase activity by dietary sucrose or fructose in man. A model for the study of enzyme regulation in man. J. Clin. Invest. 47: 2253.

13. Blair, D. G. R., W. Yakimets, and J. Tuba. 1963. Rat intestinal sucrase. II. The effects of rat age and sex and of diet on sucrase activity. Can. J. Biochem. 41: 917.

14. Deren, J. J., S. A. Broitman, and N. Zamcheck. 1967. Effect of diet upon intestinal disaccharidases and disaccharide absorption. J. Clin. Invest. 46: 186.

15. Messer, M., E. B. Thoman, A. G. Terrasa, and P. R. Dallman. 1969. Artificial feeding of infant rats by continuous gastric infusion. J. Nutrition. 98: 404.

16. Oyama, V. I., and H. Eagle. 1956. Measurement of cell growth in tissue culture with a phenol reagent (Folin Ciocalteau). Proc. Soc. Exp. Biol. Med. 91: 305.

17. Lowry, O. H., N. J. Rosebrough, A. L. Farr, and R. J. Randall. 1951. Protein measurement with the Folin phenol reagent. J. Biol. Chem. 193: 265.

18. Kopriwa, B. M., and C. P. Leblond. 1962. Improvements in the coating technique of radioautography. $J$. Histochem. Cytochem. 10: 269.

19. Schimke, R. T., and D. Doyle. 1970. Control of enzyme levels in animal tissues. Ann. Rev. Biochem. 39: 929. 
20. Kenney, F. T. 1962. Induction of tyrosine- $\alpha$-ketoglutarate transaminase in rat liver. IV. Evidence for an increase in the rate of enzyme synthesis. J. Biol. Chem. 237: 3495 .

21. Tomkins, G. M., T. D. Gelehrter, D. Granner, D. Martin, Jr., H. H. Samuels, and E. B. Thompson. 1969. Control of specific gene expression in higher organisms. Science (Washington). 166: 1474.

22. Greengard, O. 1970. The developmental formation of enzymes in rat liver. In Biochemical Actions of Hormones. G. Litwack, editor. Academic Press, Inc., New York. 53.

23. Raiha, N. C., and M. P. Kekomaki. 1968. Studies of the development of ornithine-keto acid aminotransferase activity in rat liver. Biochem. J. 108: 521.

24. Herzfeld, A., and O. Greengard. 1969. Endocrine modification of the developmental formation of ornithine aminotransferase in rat tissues. J. Biol. Chem. 244: 4894.

25. Doell, R. G., G. Rosen, and N. Kretchmer. 1965. Immunochemical studies of intestinal disaccharidases during normal and precocious development. Proc. Nat. Acad. Sci. U. S. A. 54 : 1268.

26. Das, B. C., and G. M. Gray. 1970. Intestinal sucrase: in vivo synthesis and degradation. Clin. Res. 18: 378. (Abstr.) 